\title{
ESTRATÉGIA DE INOVAÇÃO NO CLUSTER CALÇADISTA DO ESTADO DO RIO GRANDE DO SUL
}

\section{INNOVATION STRATEGY IN THE FOOTWEAR CLUSTER OF THE STATE OF RIO GRANDE DO SUL}

\author{
Adriano Cristian Gewehr \\ Universidade do Vale do Rio dos Sinos - Unisinos, São Leopoldo, RS \\ tenoacg@yahoo.com.br
}

Submissão: $17 / 07 / 2018$

Aprovação: 13/02/2019

\begin{abstract}
RESUMO
O cluster calçadista deste estado tem notória participação no cenário brasileiro e na pauta de exportações. Cluster este que, sofreu com o ataque de grandes concorrentes mundiais competindo em baixo custo dentre outros fatores macroeconômicos. O estudo busca compreender com um olhar para a inovação, como um grande fornecedor de insumos têxteis deste cluster sobreviveu às situações diversas. A pesquisa procura identificar se há existência de alguma estratégia de inovação seguindo a taxonomia proposta por Tigre (2006) e Freeman $\&$ Soete (2006). A coleta de dados se deu em: i) estudos setoriais do setor calçadista; ii) dados extraídas do INPI, da PINTEC (2008) e da PINTEC (2011); iii) entrevistas semiestruturadas com a gestão da empresa; iv) pesquisa documental em relatórios contábeis permitidos pela empresa. Constatou-se que a empresa investe significativamente acima dos padrões da indústria no quesito inovação. Como principal resultado destaca-se que, a empresa não apenas manteve-se no mercado, como experimentou melhorias consideráveis nos resultados econômicos a partir da implantação de estratégia de inovação ofensiva. O estudo demonstrou ainda que, a adoção de uma estratégia de inovação deve estar ligada implicitamente na estratégia da empresa, como fonte de geração de vantagem competitiva.
\end{abstract}

Palavras-chave: Cluster calçadista; Estratégia de inovação; Competitividade.

\begin{abstract}
The shoe industry of this state has a great participation in the Brazilian scenario and the export schedule. That industry, suffered with the attack of great foreign manufacturers wich competing in low cost, among others macroeconomic aspects. The study seeks to understand with a look at innovation, as a large supplier of textile materials of this industry survived the various situations. The study seeks to identify if there is any innovation strategy following the taxonomy proposed by Tigre (2006) and Freeman \& Soete (2006). The data was collected in:
\end{abstract}


i) studies of the footwear sector; ii) research extracted from INPI, PINTEC (2008) \& PINTEC (2011); iii) semi-structured interviews with the company management; iv) documentary research in accounting reports allowed by the company. It was found that the company invests significantly above of the industry standards in the area of innovation. The main result was to verify the company not only remained in the market, but experienced improvements on profit from innovative offensive strategy. The study also showed that, the adoption of an innovation strategy must be implicitly linked to the company's strategy, as a source of generation of competitive advantage.

Keywords: Cluster of shoes manufacturing; Innovation strategy; Competitiveness. 


\section{INTRODUÇÃO}

Existem 12 pólos calçadistas no Brasil, e, em 2004 o cluster do VS era o maior do mundo (HANSEN et al, 2004). No ano de 2012, haviam neste vale aproximadamente 380 fabricantes de todos os portes e tipos de produtos da cadeia, que empregavam quase dez mil trabalhadores (ABICALÇADOS ${ }^{1}$, 2013; COUROMODA, 2014). Ao passo que, o Vale do Paranhana - RS figura entre os quatro maiores pólos calçadista do Brasil (ASSINTECAL ${ }^{2}$, 2015).

Em 2010, o cluster calçadista do RS detinha 47,9\% das exportações de calçados do Brasil contra 26,9\% do Ceará, medidas em dólares. Nos anos posteriores, apesar de mantida a liderança no cenário nacional, o cluster do RS veio declinando este indicador, encerrando 2014 com 36,3\% contra os 29,1\% do Ceará (ABICALÇADOS, 2015). Ao passo que, as exportações medidas em pares demonstram o estado do RS apenas na terceira colocação com $13,9 \%$ do volume nacional, atrás do Ceará com 43,5\% e da Paraíba com 21,5\% (ABICALÇADOS, 2015). Esta contrariedade entre a liderança absoluta durante medida a termos monetários e a terceira colocação medida em volumes, sugere o processo de aperfeiçoamento do cluster do estado em inovação e em produtos diferenciados.

A Alpha indústria têxtil Ltda., objeto de estudo, foi fundada no ano de 1995, na cidade de Novo Hamburgo - RS, e atua como fornecedora de insumos de tecidos para calçados de todos os gêneros (predominantemente femininos) e para bolsas. Seu faturamento mensal permite enquadrá-la como de médio a grande porte. Atua no mercado calçadista do Sul, Sudeste e Nordeste do Brasil, sendo que $95 \%$ do seu faturamento é destinado ao cluster calçadista, na sua maioria produtores de calçados femininos. Aproximadamente $75 \%$ do seu faturamento está concentrado no cluster calçadista do estado do RS. Dos sete principais compradores calçadistas, apenas um tem predominância de produtos padronizados (commodities) em seus pedidos, sendo que o restante adquire produtos diferenciados. Atuante no RS, com duas unidades produtivas e uma loja de varejo está em fase de implantação de uma planta industrial no nordeste do Brasil.

O estudo discute o seguinte problema: É possível identificar alguma estratégia de inovação em uma empresa fornecedora de insumos têxteis para o cluster calçadista do $\mathrm{RS}^{3}$ ? Nesse sentido, tem como objetivo identificar se há existência de algum tipo de estratégia de inovação seguindo a taxonomia proposta por Tigre (2006) e Freeman e Soete (2006). Adicionalmente como objetivo específico, averiguar impactos nos resultados econômicos e de posicionamento como função direta da adoção da estratégia de inovação identificada.

\section{REFERENCIAL TEÓRICO}

Uma empresa pode inovar realizando inovações incrementais ou radicais. Inovações incrementais são aquelas associadas a melhorias contínuas em processos (ganhos de produtividade e redução de custos) e produtos (qualidade dele) já existentes, sem necessariamente alterar a estrutura. Já a inovação radical, caracteriza-se pela introdução de um novo produto, processo ou nova forma de organização do negócio. Pode representar uma ruptura estrutural de tal modo que, possa surgir a partir desta, um novo setor e/ou mercado (TIDD; BESSANT; PAVITT, 2008).

\footnotetext{
${ }^{1}$ Associação Brasileira das Indústrias de Calçados

${ }^{2}$ Associação Brasileira de Empresas de Componentes para Couro, Calçados e Artefatos

${ }^{3}$ Estado do Rio Grande do Sul
} 
Uma vez realizada a opção da empresa em qual tipo de inovação atuar, dado o contato micro e macroeconomico, esta pode ainda selecionar uma estratégia inovativa a perseguir que melhor se ajuste ao planejamento estratégico e o posicionamento dela. Segundo Tigre (2006) a estratégia de inovação é um subconjunto da estratégia competitiva. Seus estudos bem como os de Freeman e Soete (2006) propõem seis tipos de estratégias tecnológicas, a saber: ofensiva, defensiva, imitativa, dependente, tradicional e oportunista. O quadro 1 que segue sumariza a cada uma delas:

Quadro 1 - Estratégias de inovação segundo Tigre (2006) e Freeman \& Soete (2006)

\begin{tabular}{|l|l|}
\hline \multicolumn{1}{|c|}{$\begin{array}{c}\text { ESTRATÉGIA DE } \\
\text { INOVAÇÃO }\end{array}$} & \multicolumn{1}{|c|}{ CARACTERIZAÇÃO } \\
\hline OFENSIVA & $\begin{array}{l}\text { Quando a empresa deseja assumir a ponta em seu segmento. A inovação } \\
\text { encontra-se tanto no produto, processo e modelo de negócio. }\end{array}$ \\
\hline DEFENSIVA & $\begin{array}{l}\text { Copia os inovadores, mas apresenta melhorias a partir de observações aos } \\
\text { erros inerentes ao processo enfrentado pelos pioneiros. }\end{array}$ \\
\hline IMITATIVA & $\begin{array}{l}\text { Não pretende liderar nem obter lucros de monopólio. Quanto maior a proteção } \\
\text { ao mercado local maior a viabilidade dessa estratégia. Executa-se } \\
\text { principalmente em aspectos logísticos. }\end{array}$ \\
\hline DEPENDENTE & $\begin{array}{l}\text { Não possui iniciativa de promover mudanças técnicas de produto e/ou } \\
\text { processo, a não ser por demanda explícita de clientes e controladores. } \\
\text { Dependem de outras empresas para instruções técnicas. }\end{array}$ \\
\hline TRADICIONAL & $\begin{array}{l}\text { Produto inalterado. Pequenas ações incrementais a nível de processo e design. } \\
\text { Opera em condições de concorrência perfeita. }\end{array}$ \\
\hline OPORTUNISTA & $\begin{array}{l}\text { Explora nichos ou oportunidades temporárias. Chegar rápido ao mercado para } \\
\text { suprir uma lacuna de demanda específica. }\end{array}$ \\
\hline
\end{tabular}

Fonte: elaborado pelo autor com base em Tigre (2006) e Freeman \& Soete (2006)

Adicionalmente, vale ressaltar que, na estratégia ofensiva, a patente desempenha um papel fundamental para a manutenção da liderança de mercado, ou seja, conservação de uma posição monopolística. Vai assegurar a empresa um nível de preços que permita a recuperação do investimento em $\mathrm{P} \& \mathrm{D}$, e, posteriormente desfrutar de maiores lucros (FREEMAN; SOETE, 2006).

\subsection{PANORAMA DA INDÚSTRIA CALÇADISTA GAÚCHA}

Durante os anos 1990, surgiram dois grandes concorrentes: Índia e China. Este acontecimento forçou algumas das empresas deste cluster a concorrerem por meio de baixo preço e, consequentemente, erodindo os lucros dos demais participantes da cadeia. Humphrey e Schmitz (2000) apontam que, perseguir baixos preços foi um equívoco dos integrantes do cluster, evoluindo-se operacionalmente nas atividades, mas, negligenciando-se a evolução da criação de valor (em design, marketing e comercialização). Costa (2006) confirma que, as empresas participantes do cluster, que buscaram desenvolver estratégia em diferenciação, foram pouco afetadas pelo ingresso dos chineses. Daí a importância, segundo Kay (1993), dos estudos sobre estratégia e competitividade que procuram explicar e verificar formas de orientar determinada indústria na busca pela vantagem competitiva mais adequada. A seguir o quadro 2 que descreve analiticamente o cluster calçadista, setor comprador da empresa Alpha no estudo de caso: 


\section{Quadro 2 - Caracterização do mercado comprador da Alpha (cluster calçadista)}

\begin{tabular}{|c|c|}
\hline CARACTERÍSTICA & ANÁLISE DO CLUSTER CALÇADISTA \\
\hline $\begin{array}{l}\text { C1.Concentração do mercado } \\
\text { comprador }\end{array}$ & $\begin{array}{l}\text { Estrutura de mercado apresenta queda no grau de concentração desde 2008; foi mais concentrada entre } 1991 \text { e } 1998 \text { (LOPES, } 2012 \text { ); Ou seja, } \\
\text { tem-se alto índice de concorrência (leia-se diminuição do poder de barganha). }\end{array}$ \\
\hline $\begin{array}{l}\text { C2.Representatividade dos itens } \\
\text { têxteis nos custos do calçadista }\end{array}$ & $\begin{array}{l}\text { 11,8\% em geral; } 15,1 \% ; 3^{\circ} \text { tipo de insumo mais usado se for calçado feminino (ASSINTECAL, 2011); Desde } 2004 \text { a participação do tecido no } \\
\text { cabedal quase triplicou a participação no produto calçado feminino (ASSINTECAL, 2011). }\end{array}$ \\
\hline C3.Tipologia dos produtos & $\begin{array}{l}\text { Predominância atual de produtos diferenciados (LOPES, 2012); Indústria calçadista sinaliza migração do perfil com foco em baixo custo para } \\
\text { ofertarem elementos de diferenciação (ABICALÇADOS, 2014; SCHMIDT, 2011; CAMPOS; CALLANDRO, 2009). Inovações dos calçadistas } \\
\text { são em design, buscando a diferenciação (CGEE,2008). Analisando-se o setor pela taxonomia da Pavitt (1984) constata-se classificar as } \\
\text { empresas calçadistas como "dominadas pelo fornecedor" (GUIDOLIN, COSTA e ROCHA, 2010; ZAWISLAK, 1995). Ou seja, suas fontes de } \\
\text { inovação são predominantemente externas: tecnologias utilizadas no setor acabam sendo ditadas por fornecedores de matérias primas e } \\
\text { maquinário. }\end{array}$ \\
\hline C4.Custos da mudança & $\begin{array}{l}\text { Custos altos => preferível manter parceria => Pois: observa-se que calçadistas estão mais próximas das alianças transacionais do que das } \\
\text { estratégicas; as alianças com concorrentes são inexpressivas - predominam as competitivas com fornecedores e clientes (GIANISELLA; } \\
\text { SOUZA; ALMEIDA, 2008) }\end{array}$ \\
\hline C5.Sobre os lucros da indústria & $\begin{array}{l}\text { Margens esmagadas: i) estratégias de redução de custos foram prioridades por muito tempo; ii) há sinalização de busca pela diferenciação } \\
\text { dada a evolução de gastos em P\&D; iii) baixas barreiras a entradas e necessidade de alta escala para sobrevivência (LOPES, 2012). Políticas } \\
\text { macroeconômicas ocasionaram e ocasionam lucros reduzidos no setor calçadista (SCHREIBER; PUFFAL; TONDOLO, 2012; } \\
\text { FRANCISCHINI; AZEVEDO, 2003); em especial o câmbio em } 2014 \text { (ABICALÇADOS, 2014); Margens maiores para os fabricantes que } \\
\text { privilegiam mercado interno devido ao controle de marcas e canais de comercialização (CGEE, 2008). Margens médias de -13,6\% a 12,5\% } \\
\text { (CORRÊA, 2001); Margens médias estagnadas 9,3\% a 10,8\% (BOVESPA, 2014). }\end{array}$ \\
\hline $\begin{array}{l}\text { C6.Possibilidades de integração } \\
\text { vertical. }\end{array}$ & $\begin{array}{l}\text { Em Schneider, Diehl e Hansen (2011) é possível observar ameaça crível à integração. Há uma grande calçadista do estado ainda com elevado } \\
\text { grau de verticalização de operações, e outra grande que integrou operações, embora não relativas à manufatura de componentes, pois como } \\
\text { encontrado em Dal-Soto (2004) em análise sobre o setor de componentes que constatou crescimento deste, justamente em função da } \\
\text { desverticalização realizada pelos calçadistas, que passaram a se concentrar mais na montagem e na qualidade do calçado em si. A } \\
\text { especialização das empresas da cadeia de componentes demonstrou aos calçadistas ser mais em conta transacionar no mercado do que gerir os } \\
\text { custos de improdutividade e carregamentos dos estoques. Baixa ocorrência de integração vertical de fato (LOPES, 2012; NORONHA; } \\
\text { TURCHI, 2002); A integração vertical não se mostra com uma característica estrutural desta indústria na região estudada. A indústria calçadista } \\
\text { deste vale desestimula a integração vertical. Pelo fato da maioria das empresas fazerem parte de um cluster, espera-se que adquirir matérias } \\
\text { primas dos fornecedores seja mais viável do que a fabricação própria (LOPES, 2012); Lideranças empresariais confirmam tal intenção } \\
\text { (NORONHA; TURCHI, 2002). Historicamente partes semi-acabadas do produto final são por definição desta indústria, adquiridos } \\
\text { externamente (ANDRADE, CORRÊA, 2001). }\end{array}$ \\
\hline
\end{tabular}

Fonte: elaborado pelo autor com base na revisão bibliográfica seguindo a taxonomia de Porter (2004). 
As evidências sinalizam uma busca e seleção criteriosa de fornecedores pelos calçadistas que trabalham com apertadas margens de lucro, pois o insumo têxtil tem representatividade considerável na composição do custeio de seus produtos.

Observa-se ainda como característica deste setor: i) baixo índice de monopolização que tem por definição a contrapartida de alto índice de concorrência, ou seja, de mais empresas e baixas barreiras a entradas; ii) alteração de posicionamento, a busca de produtos diferenciados para sobrevivência, que causa aumento do poder de barganha dos fornecedores de componentes ao calçadista, tendo em vista a necessidade de customizações e o abandono de padrões que poderiam se facilmente substituídos em qualquer fornecedor a qualquer instante; iii) dependência da indústria calçadista de seus fornecedores no quesito inovação tecnológica, pois estas inovariam apenas em design; iv) custos da mudança são altos, em especial para quem trabalha com moda e diferenciação, e por isso as alianças são justamente mais transacionais que estratégicas; v) o processo de desverticalização praticado pelos calçadistas para dedicação maior a montagem e marca, permitiu especialização crescente dos fabricantes de componentes, o que por sua vez demonstrou aos calçadistas ser mais em conta transacionar no mercado do que gerir os custos de improdutividade e carregamentos dos estoques.

\section{METODOLOGIA DA PESQUISA}

3.1 CLASSIFICAÇÃO DA PESQUISA

Utilizou-se de estudo de caso como método de pesquisa, que consiste na investigação empírica de um fenômeno contemporâneo em profundidade, que permite que o pesquisador retenha as características holísticas e significativas do evento (YIN, 2010). A pesquisa é descritiva, pois objetiva relatar as características de um fenômeno - adoção de alguma estratégia inovativa pela empresa do estudo de caso - e procura correlacionar os fatos ou variáveis - efeitos na lucratividade e no posicionamento da empresa do estudo de caso - (GIL, 2008; COOPER; SCHINDLER, 2004).

\subsection{COLETA DE DADOS}

Inicialmente utilizou-se de dados secundários: i) estudos setoriais do setor calçadista, extraídos de fontes eletrônicas, como periódicos científicos e associações do setor para descrever o panorama da indústria de acordo com características propostas por Porter (2004); ii) dados extraídos do INPI $^{4}$, da PINTEC $(2008)^{5}$, e da PINTEC $(2011)^{6}$ no intuito de caracterizar a inovatividade no segmento.

Posteriormente utilizou-se de dados primários: i) entrevistas semiestruturadas que permitem ao pesquisador entender e captar a perspectiva dos agentes (ROESCH, 2010). Foram realizadas entrevistas com o gerente financeiro, o contador e o gerente de planejamento, para captar na percepção destes elementos, que atitudes a empresa tenha tomado que possam ser consideradas de caráter inovador, sendo que na fase de análise de conteúdo, permaneceram aquelas que seguem as proposições de Tigre (2006) e Freeman \& Soete (2006); ii) pesquisa documental, que possibilita o conhecimento do passado, a investigação dos processos de mudança e a ratificação de dados já obtidos (YIN, 2010; GIL, 2008). Uma vez separadas as atitudes inovadoras da empresa que se enquadram nas tipologias dos autores referenciados, e ancorando-se em princípios Schumpeterianos 7 de que a inovação precisa gerar retornos à empresa, caso contrário não passa de mera invenção, realizou-se consulta em relatórios contábeis e financeiros para identificar os impactos das atitudes inovadoras para a empresa estudada.

\footnotetext{
${ }^{4}$ Instituto nacional de propriedade industrial

${ }^{5}$ Pesquisa de inovação tecnológica realizada pelo instituto brasileiro de geografia e estatística

${ }^{6}$ Pesquisa de inovação realizada pelo instituto brasileiro de geografia e estatística

${ }^{7}$ Joseph Alois Schumpeter, economista austríaco, estudioso de inovação e organização industrial.
} 
Com relação aos impactos financeiros: i) a margem é calculada como o resultado final da empresa (lucro líquido) sobre a receita líquida (livre de impostos): Margem líquida $=$

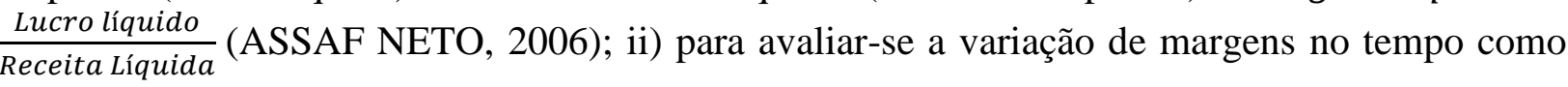
função da estratégia inovativa da empresa, utilizou-se da técnica de análise horizontal (IUDÍCIBUS, 2008; PADOVEZE, 2000); iii) realizado tal análise tanto com os lucros registrados nas demonstrações contábeis como com o lucro do exercício de 2006 trazido a valor presente para o último exercício de análise. Isto foi feito para assegurar que, em se constatando melhoria de margens, este fenômeno fosse uma função da estratégia de inovação adotada. Desta maneira movimentaram-se as seguintes contas: 1) o C.P.V. ${ }^{8}$ do exercício de 2006 na variação da taxa de câmbio do dólar de cada exercício de 2006-2014 proporcionalmente a saída de produtos vendidos que continham insumos importados na sua estrutura, ao passo que também foi ajustada na inflação; 2) despesas ajustadas na inflação do período; 3) receita líquida ajustada na inflação de cada exercício, presumindo-se um ajuste mínimo de preços. Para medida de inflação do período 2006-2014 utilizou-se do IPCA $^{9}$ disponível no IBGE $^{10}$. As taxas de câmbio no referido período, para apuração do impacto desta variável foram extraídas do IPEA ${ }^{11}$.

\section{ANÁLISE DE DADOS E DISCUSSÃO DOS RESULTADOS}

\subsection{IDENTIFICAÇÃO DA ESTRATÉGIA ADOTADA}

As duas seções subseqüentes retratam os dados coletados na Alpha e a partir de sua análise identificam qual a tipologia mais adequada conforme as proposições de Tigre (2006) e Freeman \& Soete (2006).

\subsubsection{Dados qualitativos}

Duas atitudes inovadoras dentre àquelas apontadas pelas lideranças da Alpha durante as entrevistas merecem destaque especial. Ambas estão descritas no quadro 3 que segue:

Quadro 3 - Atitudes inovadoras selecionadas a partir da coleta via entrevista

\begin{tabular}{|c|c|c|c|c|c|}
\hline $\begin{array}{l}\text { INOVAÇÃO } \\
\text { DE: }\end{array}$ & DESCRIÇÃ̃ & ANO & TIPO & $\begin{array}{c}\text { FONTES } \\
\text { (TIGRE, 2006) }\end{array}$ & RECURSOS \\
\hline Processo & $\begin{array}{l}\text { Importação de maquinário } \\
\text { Alemão. }\end{array}$ & 2008 & Incremental & $\begin{array}{l}\text { Tecnologia } \\
\text { incorporada; } \\
\text { Conhecimento } \\
\text { codificado; } \\
\text { Aprendizado } \\
\text { cumulativo }\end{array}$ & $\begin{array}{l}\text { Natureza } \\
\text { financeira: i) } \\
\text { capital próprio; } \\
\text { ii) capital de } \\
\text { terceiros; } \\
\text { Treinamento e } \\
\text { capacitação de } \\
\text { mão de obra } \\
\text { direta } \\
\text { manutenção. }\end{array}$ \\
\hline Negócio & $\begin{array}{l}\text { Parceria com instituição } \\
\text { acadêmica para alunos de } \\
\text { moda e design } \rightarrow \text { Criação } \\
\text { de um departamento para } \\
\text { pesquisa mercadológica e } \\
\text { produto. }\end{array}$ & 2008 & Radical & $\begin{array}{l}\text { Contratos de } \\
\text { transferência } \\
\text { tecnológica; } \\
\text { Conhecimento } \\
\text { tácito }\end{array}$ & $\begin{array}{l}\text { Aquisição de } \\
\text { conhecimento }\end{array}$ \\
\hline
\end{tabular}

Fonte: elaborado pelo autor a partir das entrevistas na Alpha

\footnotetext{
${ }^{8}$ Custo do Produto Vendido

${ }^{9}$ Índice de preços ao consumidor amplo. Apresenta o custo de vida de famílias que possuem renda entre 1 e 40 salários mínimos com base em 9 regiões metropolitanas do país.

${ }^{10}$ Instituto brasileiro de geografia e estatística

${ }^{11}$ Instituto de Pesquisa Econômica Aplicada
} 
As atitudes inovadoras da Alpha, estão relacionadas a: i) alterar significativamente o processo produtivo; ii), remodelagem do negócio; iii) além de que a soma de ambos produziu efeitos de criação de mercado, provendo soluções customizadas para determinados clientes. Sendo assim, cabe referenciar a estratégia como ofensiva, visto que suas características atendem ao que Tigre (2006) e Freeman \& Soete (2006) determinam como tal.

Com relação a tipologia especificamente das duas atitudes, cabe classificá-las como incremental e radical. A importação de maquinário alemão, apesar de revolucionar muitos processos, encaixa-se como incremental visto que o período para aquisição e treinamento da mão de obra ocorreu em um ano e gradualmente foram sendo aprimorados os níveis de qualidade do produto e de produtividade. No entanto, a criação do setor de pesquisa que permitiu a empresa preencher necessidades customizadas de clientes, antes sem solução, ou seja, criando mercado, pode ser classificada como radical.

Realizando-se comparativo das fontes de inovação da Alpha com as fontes de inovação da indústria brasileira, percebe-se que: i) a estratégia ofensiva adotada pela Alpha faz oposição a média geral da indústria manufatureira brasileira, que converge para adoção de imitativa ou dependente (TIGRE, 2006); ii) também está alinhada com a principal fonte de inovação no cenário da industria nacional: a aquisição de máquinas e equipamentos de tecnologia (PINTEC, 2008; PINTEC, 2011).

\subsubsection{Dados quantitativos}

Aqui se tratam dos dados contábeis/financeiros com conectividade direta à atitude inovadora da empresa. Destaca-se que, os dados aqui transpostos, sofreram preparação para o serem somente em termos relativos, uma vez que em termos absolutos não foram permitidos a sua divulgação por parte das lideranças da empresa. A tabela 1 que segue trata o investimento e os custos referentes a adoção de nova estratégia por parte da empresa no ano da decisão:

Tabela 1 - Efeitos da adoção de estratégia ofensiva

\begin{tabular}{|c|c|c|}
\hline \multicolumn{3}{|c|}{ INVESTIMENTO EM MÁQUINÁRIO } \\
\hline & & $\underline{2008}$ \\
\hline Inv. como propor. Receita & & $4,2 \%$ \\
\hline Inv. como propor. Margem lucro & & $59,5 \%$ \\
\hline \multicolumn{3}{|c|}{ CRIAÇÃO SETOR DE PESQUISA } \\
\hline Gastos com pessoas & Mês & $\underline{\text { Ano }}$ \\
\hline Custo como propor. Receita & $0,68 \%$ & $0,68 \%$ \\
\hline Custo como propor. Margem lucro & $9,6 \%$ & $9,64 \%$ \\
\hline Gastos com a pesquisa & $\underline{\text { Mês }}$ & $\underline{\text { Ano }}$ \\
\hline Custo como propor. Receita & $2,00 \%$ & $0,83 \%$ \\
\hline Custo como propor. Margem lucro & $28,6 \%$ & $11,9 \%$ \\
\hline
\end{tabular}

Fonte: elaborado pelo autor com base na pesquisa documental dos registros contábeis

Levando-se em conta a aquisição de maquinaria alemã por esta empresa como uma inovação (devido a remodelagem de processos, aos ganhos de produtividade e especialmente a customização de soluções aos clientes), observa-se que em termos relativos a empresa investiu 
consideravelmente acima dos padrões de gastos destinados a inovação por parte das empresas neste período. Uma vez que entre 2008-2011: i) as industrias que mais investiram (aeroespacial, farmacêutica, eletrônica, de informática, telecomunicações e de instrumentos) como proporção da receita líquida, realizaram $1,89 \%$ para $2,28 \%$ respectivamente; ii) a industria de média-alta intensidade tecnológica (material elétrico, veículos automotores, química, ferroviária e de equipamentos de transporte, máquinas e equipamentos) realizou $1,13 \%$ para $1,27 \%$. Em linhas gerais no referido período a indústria como um todo investiu $2,56 \%$ das receitas líquidas em inovações tecnológicas (REVISTA DIGITAL, 2014). Os gastos da Alpha com a criação do setor de pesquisa também estão ligeiramente acima da média geral registrada em 2008 pelo IPEA, que neste exercício notificou que a indústria da transformação como um todo, investia $0,75 \%$ da receita líquida de vendas em pesquisa e desenvolvimento (REVISTA DIGITAL, 2014).

Uma empresa que atua em estratégia ofensiva, leva em consideração que seus concorrentes têm acesso às mesmas informações de mercado que estão disponíveis a todos, assim devem investir forte em P\&D dentro da empresa, no intuito de desenvolver conhecimentos técnicos que extrapolam aqueles já disponíveis no mercado (FREEMAN; SOETE, 2006). Parece que a Alpha adere a estratégia ofensiva seguindo a esta recomendação, visto seus níveis de investimento e esforços em inovar.

Verifica-se ainda que a empresa onerou sua estrutura de custos fixos, lançando mão de uma parte da margem neste exercício de 2008, a partir da implementação do setor de pesquisa. Os impactos destas decisões estão evidentes na tabela que segue:

Tabela 2 - Analise horizontal de margens

\begin{tabular}{|c|c|c|c|c|c|c|c|c|c|}
\hline MÉTRICA & 2006 & 2007 & 2008 & 2009 & 2010 & 2011 & 2012 & 2013 & 2014 \\
\hline MARGENS LUCRO & $8,2 \%$ & $7,8 \%$ & $5,5 \%$ & $9,8 \%$ & $10,3 \%$ & $11,0 \%$ & $11,5 \%$ & $11,9 \%$ & $12,1 \%$ \\
\hline RENDIMENTO MARGINAL & & & & $1,8 \%$ & $0,5 \%$ & $0,7 \%$ & $0,5 \%$ & $0,4 \%$ & $0,2 \%$ \\
\hline CRESCIMENTO EM RELAÇÃO A MÉDIA 06/07 & & & & $22,5 \%$ & $28,8 \%$ & $37,5 \%$ & $43,8 \%$ & $48,8 \%$ & $51,3 \%$ \\
\hline TAXAS CRESCIMENTO & & & & & $6,3 \%$ & $8,8 \%$ & $6,3 \%$ & $5,0 \%$ & $2,5 \%$ \\
\hline
\end{tabular}

Fonte: elaborado pelo autor com base na pesquisa documental dos registros contábeis

Esta tabela evidencia os impactos positivos da estratégia de inovação da Alpha em uma concepção Schumpeteriana. Desconsiderando-se o ano de 2008 que se estabelece como o ano em que a decisão introduziu novos custos a empresa e, assumindo-se uma margem média para empresa de 8,0\% (entre 2006 e 2007), verifica-se que as margens cresceram mais de $43 \%$ até que os ganhos passassem para uma fase de rendimento marginal decrescente: Crescimento $=$ $\left[\frac{\text { Margem do exercício }}{[(\text { Margem 2006+Margem2007)/2 }]}\right]-1$. Para assegurar na análise que a melhora das margens se deu em grande parte pela estratégia de inovação ofensiva, realizou-se o seguinte procedimento: se trouxe a valor presente a margem do exercício de 2006, e este valor quando confrontado com as margens atuais, demonstra um ganho real de $30,1 \%$. De fato não se podem refutar os impactos positivos que a estratégia de inovação da empresa a trouxe. A próxima tabela ordena hierarquicamente os compradores da Alpha pelo faturamento em reais, e demonstra as margens auferidas e o tipo de produto em cada comprador: 
Tabela 3 - Margens por comprador

\begin{tabular}{|c|c|c|c|c|}
\hline \multicolumn{2}{|c|}{ EMPRESA } & \multirow{2}{*}{$\begin{array}{c}\% \text { DO } \\
\begin{array}{c}\text { FATURAMENTO } \\
\text { MENSAL }\end{array} \\
25 \% \\
\end{array}$} & \multirow{2}{*}{$\begin{array}{r}\text { MARGEM } \\
12 \% \\
\end{array}$} & \multirow{2}{*}{\begin{tabular}{|c|} 
PREDOMINÂNCIA \\
NOS PEDIDOS DE \\
PRODUTO:
\end{tabular}} \\
\hline $\mathbf{1}^{\mathbf{a}}$ & A & & & \\
\hline $2^{a}$ & B & $10 \%$ & $15 \%$ & DIFERENCIADO \\
\hline $3^{a}$ & C & $8 \%$ & $10 \%$ & DIFERENCIADO \\
\hline $4^{a}$ & $\mathrm{D}$ & $5 \%$ & $8 \%$ & DIFERENCIADO \\
\hline $5^{a}$ & E & $5 \%$ & $10 \%$ & DIFERENCIADO \\
\hline $6^{\mathbf{a}}$ & $\mathrm{F}$ & $4 \%$ & $10 \%$ & DIFERENCIADO \\
\hline $7^{a}$ & $G$ & $3 \%$ & $8 \%$ & COMMODITY \\
\hline
\end{tabular}

Fonte: elaborado pelo autor com base na pesquisa documental dos registros contábeis

Dos sete principais compradores, apenas em um predomina componente de baixo valor agregado. Em geral, ocorrem baixas margens, mas que ainda são melhores que as praticadas para produtos mais simples. Verifica-se que a migração do posicionamento da Alpha é: i) alinhado com o que este segmento vem determinando aos seus compradores, no caso a diferenciação (HITT; IRELAND; HOSKISSON, 2008; GHEMAWAT, 2000); ii) assertivo, uma vez que posicionar-se em diferenciação traz melhores margens, dadas as evidências empíricas de quem estudou em profundidade o cluster calçadista do RS (SCHMIDT, 2011; CAMPOS; CALLANDRO, 2009; COSTA, 2006; HUMPHREY; SCHMITZ, 2000). Isto é captado quando se observa que as margens de produtos diferenciados da Alpha podem ser de 50\% a $88 \%$ maiores que as praticadas em produtos padrão de baixo valor agregado (verifica-se presença de apenas uma empresa adquirente da categoria produto padrão no ranking liberado).

Em suma, pode-se dizer que, a estratégia de inovação ofensiva da Alpha, lhe garantiu vantagem competitiva em diferenciação, que ocorre quando a empresa se destaca em relação às demais por ofertar algo que desperte valor singular aos seus compradores. E percebe-se esta como o resultado da estrutura e da dinâmica do setor em que a empresa atua (MARCOVICH, 1992; COUTINHO; FERRAZ, 1994).

\subsection{ANÁLISE DA INOVATIVIDADE DENTRO DO SETOR CALÇADISTA MEDIDA A} TERMOS DE PATENTES NO PERÍODO DE 1993 A 2014

Esta seção está destinada a descrever analiticamente o comportamento da inovatividade do setor calçadista a luz da solicitação de patentes. A grandeza utilizada referencia "patentes depositadas", o que não necessariamente significa que já tenham sido deferidas (podem estar em processo de avaliação), mas captam o esforço no sentido de registrar a inovação relacionada ao setor da pesquisa. Estes dados foram extraídos do site do INPI, sendo selecionados por meio do seguinte filtro: solicitações de patentes que continham a palavra "calçados" no título.

Montou-se uma base desde os anos 1972, que aqui por conveniência, graficamente apresenta-se apenas a partir de 1993. O gráfico abaixo ilustra o comportamento (leia-se esforços em se registrar patentes) da inovatividade desta indústria no recorte temporal destacado: 
Gráfico 1 - Patentes solicitadas pelo setor calçadista brasileiro

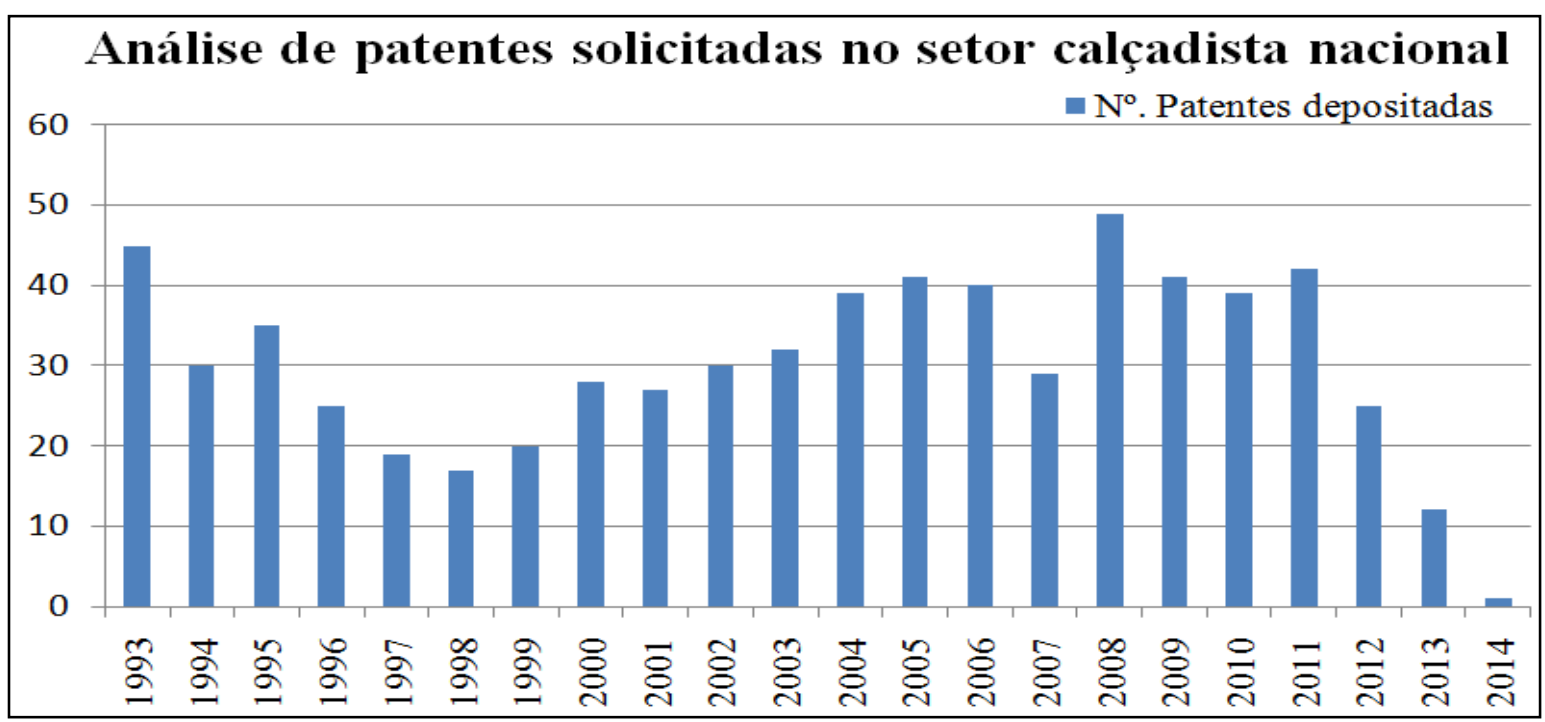

Fonte: elaborado pelo autor com base no levantamento quantitativo do site do INPI

Duas inferências emergem a partir da análise gráfica: i) observa-se um vale durante um período (ingresso dos chineses e indianos) em que justamente esta indústria deveria ter realizado mais esforços inovadores para brigar por diferenciação e não em baixo custo como ocorreu, e que por sua vez trouxe como conseqüência a "morte" de diversas indústrias; ii) um pico no exercício de 2008, justamente o ano em que a Alpha adotou medidas inovadoras em sua estratégia.

O próximo gráfico representa a abertura das patentes requeridas em três grupos do setor calçadista a nível nacional (do próprio calçadista e fornecedores):

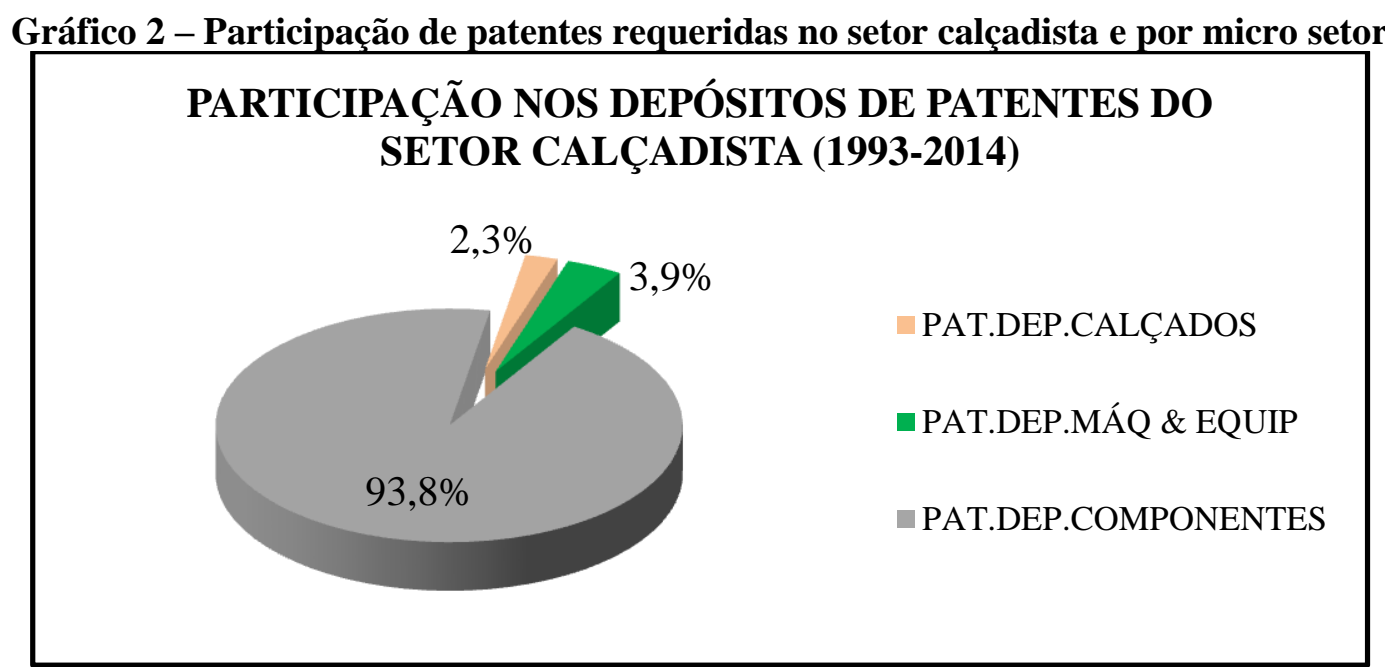

Fonte: elaborado pelo autor com base no levantamento quantitativo do site do INPI

Esta figura revela que a inovatividade deste setor medida a termos de patentes depositadas, descreve fielmente o que diversos estudos realizados demonstraram: a inovação do calçadista é ditada pela tecnologia de fornecedores (máquinas e equipamentos) e nos materiais que utiliza (micro setor de componentes). 
A seguir uma tabela que descreve a relação dos depósitos de patentes entre os têxteis calçadistas frente ao setor consolidado, e, entre os têxteis calçadistas frente ao micro setor de componentes para calçados:

Tabela 4- Relativização dos depósitos de patentes dos têxteis calçadistas em relação ao produtor de calçados e em relação ao seu micro-setor de componentes para calçados

\begin{tabular}{r|r|r}
\hline EXERCÍCIO & $\begin{array}{c}\text { EM RELAÇÃO } \\
\text { AO SETOR }\end{array}$ & $\begin{array}{c}\text { EM RELAÇÃO A } \\
\text { IND.COMPONENTES }\end{array}$ \\
\hline \hline 2011 & $4,8 \%$ & $4,9 \%$ \\
\hline 2010 & $2,6 \%$ & $3,1 \%$ \\
\hline 2009 & $2,4 \%$ & $2,6 \%$ \\
\hline 2007 & $3,4 \%$ & $3,4 \%$ \\
\hline 2006 & $2,5 \%$ & $2,6 \%$ \\
\hline 2004 & $2,6 \%$ & $2,8 \%$ \\
\hline 2002 & $3,3 \%$ & $3,3 \%$ \\
\hline 2000 & $3,6 \%$ & $4,2 \%$ \\
\hline
\end{tabular}

Fonte: elaborado pelo autor com base no levantamento quantitativo do site do INPI

$\mathrm{Na}$ tabela acima, os anos em que não foram identificados depósitos de patentes (igual a zero) por parte de têxteis calçadistas, foram removidos. Por fim, observa-se que há pouco esforço em inovar nos têxteis para calçados, o que só demonstra a pró-atividade e atitude empreendedora no sentido de inovação da Alpha, e indicia a qualificação de sua estratégia de inovação como ofensiva. Mesmo se a empresa não tenha solicitado patente de seus novos processos e/ou produtos (dados que não foram liberados).

Na próxima seção, embasando-se nos dados fornecidos pela PINTEC, buscou-se elucidar o quão alinhado ao cenário de inovação está a estratégia de inovação da Alpha.

\subsection{ALGUMAS CONSIDERAÇÕES SOBRE O DESEMPENHO GAÚCHO EM INOVAÇÕES E O POSICIONAMENTO DA ALPHA}

A partir de análise exploratória nos resultados das duas edições da PINTEC, verificou-se que o SI $^{12}$ gaúcho apresenta: i) fraco dinamismo na relação entre empresas e Institutos de Ciência e Tecnologia; ii) baixo financiamento privado para atividades de inovação; iii) e insuficiente transferência de pesquisadores pós-graduados das universidades para as empresas. Os mesmos determinantes destacados por diversos pesquisadores, como principais para a imaturidade do $\mathrm{SNI}^{13}$ brasileiro.

Há de se ressaltar que no RS, as relações entre empresas e Institutos de Ciências e Tecnologia (ICT), estão subdesenvolvidas, isto é corroborado uma vez que a atividade de inovação que recebe menos recursos das empresas é justamente a aquisição de conhecimento e a compra de $\mathrm{P} \& \mathrm{D}$ externo. Outra questão reside no fato das empresas gaúchas embasarem muito do seu processo de inovação em aquisição máquinas e equipamentos, negligenciando-se ao conhecimento e a P\&D. Desta maneira, há um distanciamento de universidades, enfraquecendo uma das relações mais importante em um SI, o que é perfeitamente justificado pela baixa transferência de profissionais habilitados para P\&D. A Alpha também baseou muito de sua

\footnotetext{
${ }^{12}$ Sistema de Inovação

${ }^{13}$ Sistema nacional de Inovação
} 
estratégia de inovação na aquisição de maquinário, no entanto, está um passo a frente deste paradigma, visto que buscou estabelecer parceria com instituição acadêmica e buscando profissionais para constituição de um setor de pesquisa.

Os baixos percentuais de inovação de processo e produto para o mercado nacional na indústria calçadista corroboram aquilo que alguns pesquisadores propuseram-se a avaliar no tocante ao caráter inovador: o efeito de uma indústria "dominada pelo fornecedor", que já fora abordado em seção anterior. Isto é revelado também pela diferença nos percentuais entre processo e produto e para dentro da própria empresa. Outro dado fornecido pela PINTEC que corrobora a pesquisas realizadas no cluster calçadista está no quesito "número de empresas que manifestam elevado interesse por informações advindas de:”. Os percentuais revelam baixo grau de coopetição, e cooperação, reforçando que as alianças estratégicas inexistem e prevalecem as transacionais, o que também já foi devidamente constatado na revisão bibliográfica.

Segundo as entrevistas realizadas com os gestores da Alpha, a estratégia (enquanto conjuntura das duas atitudes inovadoras aqui avaliadas) tinha como finalidades hierarquicamente definidas: i) criação de mercado; ii) manutenção do mercado já absorvido; iii) melhoria da qualidade dos produtos. Isto está em concordância com aquilo que a PINTEC descreve como impacto de alto nível considerado pelas indústrias nas atividades selecionadas, nos dois triênios. As prioridades estabelecidas pela Alpha convergem com aquilo que evidenciado na pesquisa da PINTEC, porém destaca-se que a criação de mercado, apenas o $8^{\circ}$ item na pesquisa, é o número um para gestão da Alpha.

\section{CONSIDERAÇÕES FINAIS}

As decisões da empresa no que se referem à inovação, tomadas a partir do exercício de 2008, tem um propósito claro de: i) alterar significativamente o processo produtivo; ii) remodelagem do negócio; iii) além de que a soma de ambos produziu efeitos de criação de mercado, provendo soluções customizadas para determinados clientes. Os níveis de investimento em inovação desta empresa quando comparados as médias nacionais, aliado ao baixíssimo esforço de inovação por parte de têxteis calçadistas (a julgar pelos depósitos de patentes) demonstram que a Alpha caminha na frente da média geral da indústria manufatureira brasileira, que converge para estratégia imitativa ou dependente. Constatou-se que, a Alpha adota estratégia de inovação ofensiva.

A empresa Alpha no ano da execução da estratégia, se comparada com as empresas consideradas inovadoras na amostra da PINTEC (2008), destinou "gastos em atividades inovadoras sobre as receitas" para: i) máquina e equipamentos na ordem de três vezes mais em termos relativos frente à média das empresas $(4,2 \%$ x 1,4\%); ii) atividades internas de P\&D na ordem de praticamente o dobro em termos relativos frente à média das empresas $(0,7 \%$ x $0,4 \%)$. A conjuntura da análise estabelecida aponta para condição sine qua non à saúde financeira da empresa, a busca por atitudes inovadoras, sejam elas de processo, produto ou modelo de negócio, em caráter incremental ou radical, para o enfrentamento das condições adversas de concorrência. A Alpha não apenas manteve-se no mercado, como experimentou melhorias consideráveis nos resultados econômicos a partir da implantação de estratégia de inovação ofensiva. Verificou-se que as margens cresceram mais de $43 \%$ até que os ganhos passassem para uma fase de rendimento marginal decrescente.

Pela análise deste caso, percebeu-se como fundamental à sobrevivência e continuidade de um negócio: i) a adoção de uma estratégia de inovação que deve estar ligada implicitamente na estratégia da empresa, como fonte de geração de vantagem competitiva; ii) o alinhamento que a adoção de uma estratégia de inovação por parte da empresa deve ter com a estrutura da industria e com seus compradores. 
No tocante a limitações desta pesquisa, cabe citar que, esta abordou analiticamente o panorama da indústria calçadista, uma vez que a Alpha atua exclusivamente para este cluster, ou seja, seu produto a enquadra em uma subdivisão desta indústria (micro-setor de componentes), pois não existem dados disponíveis, nem mesmo classificação específica de indústria têxtil só de cabedais / enfeites para calçados (apenas dados de patentes). A exploração de dados para indústria de componentes em geral para calçados (micro-setor), já é tarefa árdua, devido às carências estruturais de informação disponíveis, imagine-se nova subdivisão dentro desta subdivisão. Mas o fator decisivo, para uma abordagem em que se contextualiza o setor calçadista, - além do já sabido, de esta empresa pertencer a este setor e fornecer produtos exclusivamente a ele - está no fato de que, a utilização de dados da indústria têxtil agregada, obviamente não refletiria os propósitos deste caso, pois contaminaria a análise com dados que nada tem haver, como por exemplo, vestuário (roupas) e outros derivados desta indústria (de utilidade doméstica e industrial). 


\section{REFERÊNCIAS}

ABICALCADOS. Ano fecha com indicadores negativos para calçadistas. Disponível em: <http://www.abicalcados.com.br/site/noticias_detalhes.php?id=448\&titulo=ano-fecha-comindicadores-negativos-para-calcadistas>. Acesso em: 24 de Jan, 2015.

ABICALCADOS. As perdas milionárias do setor calçadista. Disponível em: $<$ http://www.abicalcados.com.br/site/noticias_detalhes.php?id=440\&titulo=as-perdasmilionarias-do-setor-calcadista>. Acesso em: 20 de Dez, 2014.

ABICALCADOS. Comércio exterior de calçados: Exportação. Disponível em: <http://www.abicalcados.com.br/site/inteligencia.php>. Acesso em: 24 de Jan, 2015.

ASSAF NETO, A. Estrutura e análise de balanços: um enfoque econômico-financeiro. 8. ed. São Paulo: Atlas, 2006.

ASSINTECAL. Quantificação do uso de materiais na indústria calçadista. Disponível em: $<$ http://www.assintecal.org.br/noticia/quantificacao-do-uso-de-materiais-na-industria-calcadista2011-abstract>. Acesso em: 20 de Dez, 2014.

ASSINTECAL. Estudo dos pólos calçadistas brasileiros em 2011. Disponível em: <http://www.assintecal.org.br/servicos/inteligencia/polos-brasileiros>. Acesso em: 24 de Jan, 2015.

ALBUQUERQUE, E. M. Sistema Nacional de Inovação no Brasil: uma análise introdutória a partir de dados disponíveis sobre a ciência e a tecnologia. Revista de Economia Política, v. 16, n. 3 (63), jul/set, 1996.

ANDRADE, J. E. P.; CORRÊA, A. R. Panorama da indústria mundial de calçados, com ênfase na América Latina. BNDES Setorial, Rio de Janeiro, n.13, p.95-126, 2001.

BANCO NACIONAL DE DESENVOLVIMENTO ECONÔMICO E SOCIAL. Disponível em:<http://www.bndes.gov.br/>. Acesso em 8 de out. 2015.

BOVESPA.

Disponível em:

<http://www.bmfbovespa.com.br/home.aspx?idioma=pt-br> Acesso em: 20 de Dez, 2014.

CAMPOS, S. H.; CALANDRO, M. L. Nova configuração do mercado internacional de calçados e os impactos sobre a indústria calçadista gaúcha. Ensaios FEE, Estudos Setoriais, v. 30, Número Especial, p. 517-546, 2009.

CGEE - CENTRO DE GESTÃO E ESTUDOS ESTRATÉGICOS. Estudo prospectivo: cadeia coureiro-calçadista e artefatos. Série Cadernos da Indústria ABDI, v. 4. Brasília: ABDI, 2008.

COOPER, D. R.; SCHINDLER, P. S. Métodos de Pesquisa em Administração. Trad. Luciana de Oliveira da Rocha. $7^{a}$ ed. Porto Alegre: Bookman, 2004.

COSTA, A. B. O desenvolvimento econômico na visão de Joseph Schumpeter. Cadernos IHU Idéias, n. 47, p.1-22, 2006.

COSTA, A. B.; FROEHLICH, C. Trajetória empresarial em cluster calçadista brasileiro: o caso da Paquetá Calçados. Ensaios FEE, v.29, n.2, p.385-408, 2008.

COUROMODA. 7 Clusters calçadistas: Brasil, um grande player mundial. Disponível em: $<$ http://www.couromoda.com/noticias/ler/clusters-calcadistas-brasil-um-grande-player-mundialdo-calcado>. Acesso em: 20 de Dez, 2014.

COUTINHO, L. G.; FERRAZ, J. C. Estudo da competitividade da indústria brasileira. $2^{\mathrm{a}}$ Ed. Campinas: Papirus, 2004.

CORRÊA, A. R. O complexo coureiro-calçadista brasileiro. BNDES Setorial, n.14, p.65-92, 2001.

DAL-SOTO, F. O desenvolvimento de competências organizacionais para a inserção internacional: um estudo no setor de componentes para couro, calçados e artefatos do Vale 
do Sinos. 2004. 184 f. Dissertação (Mestrado em Administração), Unisinos, São Leopoldo, RS, 2004.

FINANCIADORA DE ESTUDOS E PROJETOS. Disponível em: $<$ http://www.finep.gov.br/>. Acesso em: 8 de out. 2015.

FRANCISCHINI, S. N.; AZEVEDO, P. F. Estratégias das empresas do setor calçadista diante do novo ambiente competitivo: análise de três casos. Gestão \& Produção, v.10, n.3, p.251-265, 2003.

FREEMAN, C.; SOETE, L. A Economia da Inovação Industrial. São Paulo: Unicamp, 2006.

GIANISELLA, R. L. G.; SOUZA, M. A.; ALMEIDA, L. B. Adoção de Alianças Estratégicas por Empresas dos Pólos Calçadistas do Vale do Rio dos Sinos-RS e de Franca-SP: um estudo exploratório. Revista Brasileira de Gestão de Negócios, v. 10, n. 26, p. 45-62, 2008.

GIL, A. C. Métodos e técnicas de pesquisa social. $6^{a}$ ed. São Paulo: Atlas, 2008.

GUIDOLIN,S.; COSTA, A.; ROCHA, E. Indústria calçadista e estratégias de fortalecimento da competitividade. BNDES Setorial, n.31, p. 147-184, 2010.

HANSEN, P. B.; et al.; Análise do arranjo coureiro - calçadista do RS a luz do conceito de competitividade sistêmica. Encontro Nacional de Engenharia de produção - ENGEP, Florianópolis, UFSC, Nov de 2004, v.24, p3681-3688.

HITT, M. A.; IRELAND, D. R.; HOSKISSON, R. E. Administração estratégica: competitividade e globalização. $2^{\mathrm{a}}$ ed. São Paulo: Thomson Learning, 2008.

GHEMAWAT, P. A. Estratégia e o Cenário dos Negócios. Porto Alegre: Bookman, 2000.

HUMPHREY, J.; SCHMITZ, H. (2000) - Governance and Upgrading: Linking Industrial Cluster and Global Value Chain Research. IDS Working Paper 120 - Institute of Development Studies, University of Sussex.

IBGE (2015). Instituto brasileiro de geografia e estatística: IPCA. Disponível em: < https://www.ibge.gov.br/estatisticas-novoportal/economicas/precos-e-custos/9256-indicenacional-de-precos-ao-consumidor-amplo.html?=\&t=downloads $>$. Acesso em: 2 de Out.2015.

IPEA (2015). Instituto de pesquisa e economia aplicada. Disponível em: <http://ipeadata.gov.br/Default.aspx >. Acesso em: 2 de Out.2015.

INSTITUTO NACIONAL DA PROTEÇÃO INDUSTRIAL. Disponível em: <http://www.inpi.gov.br/>. Acesso em: 8 de out. 2015.

KAY, J. The structure of strategy.Business Strategy Review, v. 4, n. 2, p.17-37, 1993.

IUDÍCIBUS, Sérgio de. Análise de Balanços. 9 ed. São Paulo, Atlas: 2008.

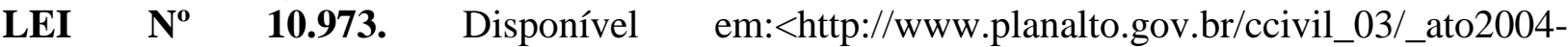
2006/2004/lei/110.973.htm>. Acesso em: 05 de out. 2015.

LEI N $\quad$ 11.196. Disponível em:<http://www.planalto.gov.br/ccivil_03/_ato20042006/2005/lei/111196.htm>. Acesso em: 05 de out. 2015.

LOPES, H. C. O Setor calçadista do Vale dos Sinos/RS: um estudo a partir do modelo EstruturaConduta-Desempenho. In:Anpec Sul, 2012. Porto Alegre: AnpecSul, 2012.

MANUAL DE OSLO - Diretrizes para Coleta e Interpretação de Dados sobre Inovação. 3. ed., OCDE (1. ed. de 1997, traduzido para o português em 2004 pela Finep). Disponível em: <http://download.finep.gov.br/imprensa/manual_de_oslo.pdf>. Acesso em: 10 de out. 2015.

MARCOVICH, J. Competitividade e Tecnologia no Brasil. Série Política Científica e Tecnológica - 11. Instituto de Estudos Avançados, 1992, 15p.

NORONHA, E. G.; TURCHI, L. M. Cooperação e conflito: estudo de caso do complexocoureiro calçadista no Brasil. Texto para discussão. IPEA, Brasília, n.861, p. 1-44, 2002.

PINTEC. Pesquisa de Inovação Tecnológica 2008, Instituto Brasileiro de Geografia e Estatística (IBGE), Rio de Janeiro, 2010. Disponível em: 
<http://www.pintec.ibge.gov.br/downloads/PUBLICACAO/Publicacao\%20PINTEC\%202008.p df $>$. Acesso em 10 out. 2015.

PINTEC. Pesquisa de Inovação Tecnológica 2011, Instituto Brasileiro de Geografia e Estatística (IBGE), Rio de Janeiro, 2013. Disponível em: <http://www.pintec.ibge.gov.br/downloads/pintec2011\%20publicacao\%20completa.pdf $>$. Acesso em 10 out. 2015.

PORTAL

ABDI

Disponível

em:

<http://www.abdi.com.br/Paginas/politica_industrial.aspx>. Acesso em: 06 out. 2015.

PORTER, Michael E. Estratégia competitiva: técnicas para análise de indústrias e da concorrência. $2^{\mathrm{a}}$ ed. Rio de janeiro: Elsevier, 2004.

PADOVEZE, Clóvis L. Contabilidade Gerencial: um enfoque em sistema de informação contábil. 3 ed. São Paulo, Atlas, 2000.

PATTON, M. Q. Qualitative Evaluation and Research Methods. Thousand Oaks. Sage, 1990. PAVITT, K. (1984) Sectoral patterns of technical change: towards a taxonomy and a theory. Revista Brasileira de Inovação, v. 2, n. 2, 2003.

REVISTA DIGITAL. Indústria brasileira amplia percentual da receita investido em P\&D.

Disponível em: <http://www.revistadigital.com.br/2014/03/industria-brasileira-ampliapercentual-da-receita-investido-em-pd/>. Acesso em 9 de out. 2015.

ROESCH, S. M. A. Projetos de estágio e de pesquisa em administração: guia para estágios, trabalhos de conclusão, dissertações e estudos de caso. $3^{\text {a }}$ ed. São Paulo: Atlas, 2010.

SCHMIDT, S. Mudanças estratégicas das empresas calçadistas do Vale do Rio dos Sinos. Revista Organizações \& Sociedade, UFBA, Salvador, v.18, n.58, p.371-388, 2011.

SCHNEIDER, L. C.; DIEHL, C. A.; HANSEN, P. B. Análise da cadeia de valor em duas empresas do setor calçadista. Revista Gestão Industrial, v. 7, n. 3, 2011.

SCHREIBER, D.; PUFFAL, D. P.; TONDOLO, V. A. G. Análise compreensiva do processo de gestão do conhecimento nas indústrias de calçados. XV Simpósio de Administração da Produção, Logística e Operações Internacionais - SIMPOI, FGV-EASP. São Paulo, 15 p., 2012.

TIDD, J.; BESSANT, J.; PAVITT, K. Gestão da inovação. $3^{a}$ ed. Porto Alegre, Bookman, 2008. TIGRE, P. B. Gestão da inovação: a economia da tecnologia no Brasil. Rio de Janeiro, Elsevier, 2006.

YIN, Robert. K. Estudo de caso: planejamento e métodos. $4^{\text {a }}$ ed. Porto Alegre: Bookman, 2010. ZAWISLAK, P. A inovação no setor calçadista brasileiro: um exemplo de atividade de resolução de problemas. In: FENSTERSEIFER, J.(Org.).O complexo calçadista em perspectiva: tecnologia e competitividade. Porto Alegre: Ortiz, 1995. p. 143-182. 